\title{
Motivational Orientation and Brand Familiarity: Positive Emotions and Skepticism toward Online Advertising Using the English Language*
}

\author{
Mei-Rong Alice Chen, Sufen Chen, Couchen Wu \\ National Taiwan University of Science and Technology, Taiwan, China
}

\begin{abstract}
Online video advertising using the English language is a trend in international marketing. While previous studies have pointed out that individuals' motivational orientation in the context of advertising plays a key role in ad preference and effectiveness, few studies have been carried out to investigate the effect of online English advertising on international consumers with different motivational orientations in non-English speaking populations. Accordingly, this article examines the effects of motivational orientation and brand familiarity on positive emotions and skepticism in international consumers' responses to online video English advertising. The results imply that participants' positive emotions can be influenced more by their motivational orientation than by their familiarity with the brand, while their skepticism can be affected more by brand familiarity than by motivational orientation toward the ad. Moreover, participants high in English promotion orientation displayed higher positive emotions toward unfamiliar brand online advertising than did the English prevention-orientated participants toward a familiar brand ad. Prevention orientation exhibits a higher level of skepticism towards an unfamiliar brand online video advertisement. The effects are more explicit in motivational orientation in English than general motivational orientation. This research suggests that generating positive emotions and reducing the skepticism of non-English-speaking individuals is essential to build brand image in online marketing.
\end{abstract}

Keywords: motivation orientation, emotions, skepticism, brand familiarity, on-line advertising

\section{Introduction}

Online video advertising using the English language is a trend in international marketing. The results of two studies show that positive emotion is influenced more by motivational orientation than by brand familiarity, while skepticism is affected more by brand familiarity than by motivational orientation in non-English-speaking consumers' responses to online video English advertising. Moreover, promotion orientation displayed higher positive emotions than did prevention orientation. Prevention orientation exhibits a higher level of skepticism than did promotion orientation. This research suggests that generating positive

\footnotetext{
*Acknowledgement: This project was supported by the Ministry of Science and Technology, Taiwan, under grant number NSC 102-2628-S-011-001-MY4. The authors thank Dr. Chin-Chung Tsai, Dr. Carol Finnegan, Mr. Art Wang, and Dr. Li-chu Sung for their insightful comments during this research process.

Mei-Rong Alice Chen, lecturer, Language Center,National Taiwan University of Science and Technology.

Sufen Chen, professor, Graduate Institute of Digital Learning and Education, National Taiwan University of Science and Technology.

Couchen Wu, professor, Marketing in Business Administration, National Taiwan University of Science and Technology.
} 
emotions and reducing skepticism of non-English-speaking consumers are essential to build brand image in online marketing.

In the Internet environment, online video advertising is an incredibly influential and trendy tool for business promotion. Since English is widely accepted and used around the world, most people watch online video English advertising regardless of whether it is for familiar or unfamiliar brands. For a familiar brand, reaching the right target segment is an essential issue (Percy \& Rossiter, 1992). However, for an unfamiliar brand, in addition to reaching the target, it is also vital to identify effective appeals to advertise rationally to affect cognition and affect (Yen, Chao, \& Lin, 2011). Based on a wealth of empirical evidence, researchers of consumer behavior have emphasized the relative roles of cognition versus affect in brand attitude formation (Homer, 2006; Sung \& Kim, 2010; Verwijmeren, Karremans, Bernitter, Stroebe, \& Wigboldus, 2013). Skepticism is a significant predictor of cognition (Peytcheva, 2013). For example, people who could not use foreign languages such as English can be distrustful and skeptical of the information in a foreign language or second language (L2) (Sohn, 2013). As for affect, positive emotion is a core variable for popular employer branding (Rampl \& Kenning, 2013). An understanding of L2 consumers' skepticism and positive emotion while watching an online English advertising can be beneficial to online marketing.

Approaches to targeting ads at international viewers and matching their segmentation aims continue to receive growing attention (Truong, McColl, \& Kitchen, 2010; Evans, 2009). In this study, two important segmentation approaches are drawn from Higgins' (1997): promotion and prevention. This research investigates the influence on brand familiarity and motivational orientations on skepticism and positive emotions and exploring the motivational orientation, each of which is discussed in the following.

Study 1 focuses on chronic motivational orientations, and study 2 focuses on motivational orientations in English as a second language (L2).

\section{Chronic Motivational Orientation}

Individuals' motivational orientation plays a key role in ad preference and effectiveness (Sung \& Choi, 2011). Consumers will react differently to identical advertising since their reactions may be aroused by their specific goals (Wolin, 2003). Higgins (1997) claimed that such a goal-directed reaction is regulated by two distinct motivational orientations, promotion orientation (PRO) and prevention orientation (PVO). Promotion-oriented individuals strive to achieve positive outcomes, while prevention-oriented individuals strive to avert negative outcomes. Specifically, promotion-oriented individuals are associated with improvement and achievement, whereas prevention-oriented individuals are linked with reliability and responsibility (Haws, Dholakia, \& Bearden, 2010).

\section{Motivational Orientation in English as a Second Language (L2)}

Higgins' (1997) promotion orientation emphasizes "hopes, accomplishments, and advancement needs. Goals are viewed as ideals, and there is a strategic concern with approaching gains (the presence of positives) and avoiding non-gains (the absence of positives)." This is closely related to Gardner and Lambert (1972) proposes. In the earlier formulation of motivation in second language (L2) acquisition, individuals' motivations in the L2 are related to their approaches toward L2 cultures and their goals. They labeled two L2 motivational orientations as "integrative" and "instrumental." "Integrative" motivation is "an interest in learning the L2 in order to interact with the L2 group, as well as positive attitudes toward these people and their culture".

Higgins' (1997) "prevention focus" emphasizes "safety, responsibility, and security needs. Goals are 
viewed as oughts and there is a strategic concern with approaching non-losses (the absence of negatives) and avoiding losses (the presence of negatives)." which is closely related to "instrumental" motivation. Gardner and Lambert (1959) defined it as "a desire to learn the L2 in order to fulfill a pragmatic objective, such as to enhance future career opportunities".

In this study, the terms "promotion" and "prevention" are used to represent "integrative" motivation and "instrumental" motivation as a combination of both Higgins" "motivational orientation" and Gardner and Lambert's "motivational orientation in L2." Individuals who are promotion-orientated in relation to English (PROE) are defined as those with a positive desire to discover the L2, and to associate with the L2 society. Gardner and Lambert (1972) suggested that individuals with a PROE would demonstrate greater motivational effort in achieving goals in the L2, and thus achieve greater L2 competence. This orientation can be differentiated from that of individuals who are prevention-orientated in relation to English (PVOE), which refers to those with a desire to use the L2 to fulfill some practical responsibilities, such as job advancement or course credit.

\section{Brand Familiarity}

When consumers decide to buy products, they tend to be affected by brand familiarity (Alba \& Hutchinson, 2000). The number of associative links in their memory would be fewer for unfamiliar than for familiar brands (Holden \& Vanhuele, 1999). Previous research shows that familiarity influences destination perceptions, information searching (Campbell \& Keller, 2003) and message processing (Holden \& Vanhuele, 1999). In general, familiar brands are more positively evaluated than unfamiliar brands (Dens \& De Pelsmacker, 2010). Thus, online video advertising performance may depend upon the target's prior familiarity with the brand.

\section{Skepticism Toward Online Video Advertising}

Previous research has conceptualized skepticism as the tendency of individuals to distrust various forms of marketing communication, including advertising, and refers to consumer distrust or disbelief in the information claims in advertisements (Obermiller \& Spangenberg, 1998). According to Obermiller and his colleagues (1998), advertisement skepticism is associated with behaviors as well as with the use of advertising information. Callister and Stern (2007) stated that individuals with high levels of skepticism tend to have an aversion to online advertising. High skepticism would tend to derive from more negative attitudes, weaker trust in information, less purchase intention (Soopramanien, 2011). Kirmani and Zhu (2007) clarified that activation of persuasion information typically involves suspicion about the marketer's concealed purposes and the online advertising claims.

\section{Positive Emotions Toward Online Video Advertising}

Emotions are "to signify stimulus of the feelings" and are evoked by the content in advertising corresponding to something that is capable of activating the feelings of the viewer (Heath, 2009). Assael (1998) made it more explicit by saying that any materials, images, or visual communications can constitute stimuli. Therefore, individuals' emotions can be a result of many stimuli, which can draw out both positive and negative emotions (Gross, 2001).To constantly attract and retain consumers' attention in video advertisements, the strategy of inducing positive emotional responses is considered a powerful approach (Lee, Lin, Liao, \& Yeh, 2013). Consequently, most marketers make every effort to ensure that their online advertising boosts positive 
emotions and enhances the attainment of the desired communication outcomes (Chapman, 2013).

Both orientations can be regulated by stimuli (Cunningham \& Johnson, 2005) which can influence their emotions and cognition (Baek \& Reid, 2013). The relationship between PRO and gains or between PVO and losses can be considered as a regulatory fit, which is essential to information processing and emotions (Pham \& Higgins, 2005).

\section{Hypotheses}

\section{H1: Concerning Skepticism}

When exposed to online video advertisements in a foreign language, consumers usually appraise the information first and tend to generate skepticism if there is insufficient information, or if they are unfamiliar with the foreign language (Zhang \& Schmitt, 2004; Sohn, 2013). L2 advertisements may cause individuals to spend more time processing the information as they need to process the ad contents as well as the brand and the foreign language (Luna \& Peracchio, 2005). In fact, L2 use involves uncertainty about how the language works (Wallace, 1991). Facing uncertainty, the cognition effect from brand familiarity will be enhanced (Forbes-Riley \& Litman, 2009). For unfamiliar notions, individuals are more likely to doubt novel information, so they may appraise information with a convinced attitude, such that, as discussed previously, a familiar brand can induce less skepticism (Förster \& Higgins, 2005). For unfamiliar brands, the situation will be even more severe. As individuals avoid uncertainty and insecurity, they may lean towards being more suspicious because of being uncertain about unfamiliar brands, and may be much more cautious about unfamiliar information, which leads to the activation of greater skepticism.

H1a: For both prevention-orientated and promotion-orientated individuals, unfamiliar brands will evoke a higher degree of skepticism. PVOE individuals desire to use English as an L2 in order to fulfill a pragmatic objective. Towards unfamiliarity, they tend to use vigilance and more suspicious means to attain prevention-relevant outcomes as is the case with English as an L2. Furthermore, as they avoid uncertainty and insecurity, they may lean towards being more suspicious because of their characteristic of being uncertain about unfamiliar brands, and may be much more cautious about unfamiliar information, which leads to activation of greater skepticism. Consequently, English online advertisements should be goal consistent for individuals high in promotion orientation related to English. Compared with promotion-orientated individuals, prevention-orientated individuals will have higher skepticism.

H1b: Prevention-orientated individuals will display a higher degree of skepticism than promotion-orientated individuals with regard to online English video advertisements for both familiar and unfamiliar brands. Homer (2006) stated that brand familiarity impacts cognition.

H1c: For skepticism, the effect of brand familiarity is greater than the degree of motivational orientations. According to Peytcheva (2013), skepticism is more associated with cognition than with affection. On the other hand, the motivational orientation effect is more consistent with heuristics than with systematic processing of information (Wang \& Lee, 2006; Ha \& Perks, 2005). As a result, the motivational orientation effect is mainly on affection. Therefore, we hypothesize that.

\section{H2: Concerning Positive Emotions}

Familiar brands can be perceived as persuasive information because it can be easily processed by consumers to induce specific positive emotions, which cannot be easily replaced by unfamiliar brands (Dens \& De Pelsmacker, 2010). In other words, familiarity is associated with positive emotions because it is 
recognizable and evokes feelings of security.

H2a: Familiar brands always evoke more positive emotions for both prevention-orientated and promotion-orientated individuals.

Previous studies have indicated that conceptual or semantic processing is different in one's L1 from in an L2 (Liang, Cherian, \& Liu, 2010). As individuals with a PRO attempt to approach novel experiences, they are characterized as having a desire for new and various experiences. They tend to pay attention to new information and use approach strategies when viewing an online video advertisement. As PROE individuals are interested in using English as an L2 in order to interact with the foreign group, as well as having positive attitudes toward these people and their culture, they will pay attention to new information and use approach strategies when viewing an online video advertisement (Chernev, 2004). For unfamiliar notions, they are more likely to accept novel information (Förster \& Higgins, 2005) than the PVO individuals, so they may appraise information with a relatively convinced attitude.

Since PROE individuals tend to accept foreign languages more easily, it can be inferred that they may generate more positive emotions. In contrast, English prevention-orientated individuals search for information in a more local manner and center negative feelings, which may infer their discomfort with or resistance to an L2 (Sohn, 2013). Therefore, promotion orientation related to English can be seen as being congruent with an individual's preferred end-state outcome. Such congruence can enhance consumer emotional responses to a brand (Aaker \& Lee, 2001).

H2b: For both familiar and unfamiliar brands, promotion-orientated individuals will display a higher degree of positive emotions than prevention-orientated individuals.

As previously mentioned, motivational orientation effect is related to affection while brand familiarity is related to cognitions. Positive emotions have a potential influence on the heuristic effect. (Bolte, Goschke, \& Kuhl, 2003). Motivational orientations related to English are associated with emotions, while brand familiarity is connected with cognition factors. PROE individuals are eager to pursue using English even though it is an unfamiliar language, which fits their orientation. They engage more positively and confidently when viewing online English video advertisements. Due to the regulatory fit effect, they feel right and strengthen their engagement; thus the cognitive effect decreases (Aaker \& Lee, 2006). On the other hand, prevention-orientated individuals related to English are in the non-fit condition. Because of the regulatory non-fit effect, they avoid the unfamiliar context, which includes not only the L2 but also the brand messages when viewing online English video advertisements. Accordingly, there might be a bigger gap of displaying positive emotions between individuals with PROE than those with PVOE. Consequently, it can be hypothesized as follows.

H2c: For positive emotions, the effect of motivational orientation is greater than the effect of brand familiarity.

The crucial function of positive emotions is considered in an affective mode as the essential component of sensation, whereas skepticism can be considered in a cognitive model of human-information behavior (Koslow, 2000). Two studies were carried out to investigate the participants' skepticism and positive emotions. Study 1, an exploratory empirical study, measured the participants' chronic promotion and prevention strength and clarified the influence of motivational orientation and brand familiarity on skepticism and positive emotions. Study 2 examined the crucial effects of English promotion orientation and English prevention orientation toward brand familiarity on skepticism and positive emotions. 


\section{Study 1}

Study 1 tested the hypotheses that for individuals in non-English speaking regions, motivational orientation, and brand familiarity of online English video advertisements influence skepticism (H1) and positive emotions $(\mathrm{H} 2)$, and was a 2 (Motivational orientation: promotion versus prevention) $\times 2$ (stimuli: unfamiliar versus familiar brand advertisements) within-subjects design.

\section{Method}

The study was conducted in classroom settings. Participants were told that the purpose was to investigate their motivational orientations. All participants were instructed orally and were distributed a questionnaire. After completing the first part of the Motivational Orientation Measure (MOM) questionnaire (see Appendix A), the participants were arranged to watch online English video ads, one familiar and one unfamiliar, in random order. Immediately after finishing watching each ad, the participants rated it on a five-point Likert scale as follows: three items (Familiar, Well-known, Seen before) assessing participants' familiarity (Leavitt, 1970), eight items assessing their positive emotions, and three items related to skepticism of the advertisement.

\section{Familiarity as Stimuli}

Two brands of toning shoes were selected from four brands in an independent study carried out by the American Council on Exercise (ACE), in which they compared the effectiveness of trendy toning shoes. The two online video ads claim that the toning shoes offer improvement in fitness and muscle activation. However, ACE's study (Porcari et al., 2010) uncovered that the shoes are not as magical as the advertisements claim. Among the four brands of shoes in their study, Skechers and New Balance are available on the Taiwanese market. Therefore, advertisements from the Skechers (http://www.skechers.com/) and New Balance (http://www.newbalance.com/wellness/truebalance-toning-shoes/) official websites were adopted as the experiment materials in this research. Both internet video advertisements were two genuine 30 seconds long. Skechers Shape-ups is an unfamiliar brand, whereas New Balance toning is a familiar brand. The advertisements were taken from the actual websites. One was Skechers Shape-ups, and the other was shoes. This distinction was validated by the survey. A paired t-test indicated that there was a significant difference in the scores for brand familiarity ( $\mathrm{t}(296)=46.20, \mathrm{p}<0.001)$ between New Balance $(\mathrm{M}=4.38, \mathrm{SD}=0.55)$ and Skechers $(\mathrm{M}=1.80, \mathrm{SD}=0.72)$.

\section{Instruments}

Motivational Orientation Measure (MOM). The first part of the Chinese version of this questionnaire presented a pool of eighteen items specifically referring to the Motivational Orientation Measure (MOM). MOM was adopted from Summerville and Roese's study (2008). MOM is reliable and valid for identifying individuals' motivation orientations. Cavallo and his colleagues (2009) also used it in their study and considered it suitable to utilize as a measure of PRO/PVO. After factor analysis, 18 items were selected for the MOM questionnaire, and were rearranged randomly to remove concerns about order effects on the promotion and prevention constructs. All items were presented on a one to five Likert scale and were anchored with endpoints "strongly disagree/strongly agree."

Participants' motivational orientation was calculated by first adding up the nine prevention items and the nine promotion items separately. Then, the sum of the promotion items was compared with the sum of the prevention items. If a participant's sum of promotion items was higher than the sum of prevention items. This participant was PRO (Cesario \& Higgins, 2008). When a participant's two sums were equal, his/her orientation 
would be based on a median split (Zhao \& Pechmann, 2007). Participants were grouped as having promotion or prevention orientations based on this computing method. Among the 296 participants, $124(41.90 \%)$ were grouped as having a PVO, and $172(58.10 \%)$ as having a PRO.

\section{Positive Emotions}

In the present study, after the participants completed the MOM, they watched the online video advertisement, and then the positive emotions adapted from Summerville and Roese's (2008) study used the Positive and Negative Affect Schedule (PANAS) (Watson, Clark, \& Tellegen, 1988) were given the participants. There were 16 items of positive and negative emotions. The eight items of positive emotions included "This online video English advertisement is interesting, attentive, attractive, exciting, enthusiastic, inspiring, favorable, and active" for both the unfamiliar and the familiar brand advertisements. Eight items had been selected and translated from English into Chinese. In the pilot study, the Cronbach's $\alpha$ of Negative emotion was low (0.16), and the exploratory factor analysis (Watson, Clark, \& Tellegen, 1988) also found to have poor construct validity regarding Negative emotion. Therefore, this construct was deleted from the questionnaire.

\section{Skepticism}

Three items related to skepticism were adopted directly from the subdimension of the Standardized Emotional Profile (SEP) - Skepticism (Holbrook \& Batra, 1987), which includes the following items: skeptical, suspicious, and distrustful. The participants ranked them on a five-point of Likert scale after each ad.

\section{Participants}

A total of 296 undergraduates were recruited from several northern Taiwan universities. They were enrolled in English courses, participated in the study, and received small gifts as compensation. The sample comprised 137 males (46.3\%) and 159 females (53.7\%). Their ages ranged from 21 to 38 with an average of 22.5 (SD 3.50). They had scored an average of 390 on the Test of English for International Communication (TOEIC). This sampling is selected because the advertised shoes are mostly targeted towards adolescents and young adults (Yoh, 2005) and these participants have potential purchasing power. In addition, the participants' competence and the effect of the English advertising message on them rely on their knowledge of English (Wyer, 2002). College students in Asia have more chance to have contact with English than working adults or other age groups (Ahn \& La Ferle, 2008). Moreover, Taiwan is located at the heart of the Asia-Pacific region and can be considered as an Asian hub. It represents typical Asian consumer societies and falls between Hong Kong and China (Tse, Belk, \& Zhou, 1989; Chang, 2010). Therefore, by employing college student participants in Taiwan, this research can test the hypotheses on a representative sample. Among the 296 participants, 124 (41.90\%) were grouped as having a PVO, while 172 (58.10\%) had a PRO.

\section{Results}

Exploratory factor analysis revealed clean loading patterns for MOM (18 items), Familiarity (three items), Skepticism (three items) and Positive Emotions (eight items). Item loadings ranged from 0.46 to 0.92. Cronbach's alpha was used to analyze the reliability of the measures, and the results exhibited desirable reliability scores ranging from 0.78 to 0.96 (See Table 1).

Table 1

Familiar Brand vs.Unfamiliar Brand Study 1 :The number of items in each construct and Cronbach's $\alpha$ 
Promotion

Prevention

Familiarity

Emotions

Skepticism

\begin{tabular}{ll} 
Item number & Cronbach's $\alpha$ \\
\hline 9 & 0.78 \\
9 & 0.82 \\
3 & $\mathrm{~F}=0.87 / \mathrm{Un}=0.91$ \\
8 & $\mathrm{~F}=0.96 / \mathrm{un}=0.96$ \\
3 & $\mathrm{~F}=0.87 / \mathrm{un}=0.83$
\end{tabular}

Participants' skepticism regarding the two online video advertisements was analyzed using repeated measures ANOVA. The results confirmed that there were significant main effects of brand familiarity (F (1, $294)=1197.59, \mathrm{p}<0.0001)$, and motivational orientation $(\mathrm{F}(1,294)=15.62, \mathrm{p}<0.0001)$ on skepticism as shown in Table 2 . The interaction effect between familiarity and motivational orientations was not significant.

Simple t-tests confirmed H1a the influence of the familiar brand (t $(295)=71.34, \mathrm{p}<0.001)$ and the unfamiliar brand $(\mathrm{t}(295)=123.84, \mathrm{p}<0.001)$ on skepticism.

Simple t-tests confirmed the hypothesis H1bthat the PVO group expressed higher skepticism than the PRO group for $\mathrm{t}(171)=26.21, \mathrm{p}<0.05$ for the PRO group and $\mathrm{t}(123)=22.65, \mathrm{p}<0.05$ for the PVO group.

The prevention-oriented participants expressed a higher degree of skepticism than the promotion-oriented group after watching the unfamiliar brand advertisement $(\mathrm{M}$ prevention/Unfamiliar $=3.59$, $\mathrm{M}$ promotion/Unfamiliar=3.44,). After watching the familiar brand ad, the prevention-oriented participants still expressed a higher degree of skepticism than the promotion-oriented group ( $\mathrm{M}$ prevention/Unfamiliar $=2.31$, $\mathrm{M}$ promotion/Unfamiliar=2.08), so H1a was supported.

The hypothesis H1b regarding two groups' skepticism was also supported: The unfamiliar brand (t (295) $=123.84, \mathrm{p}<0.001)$ always raised higher skepticism than the familiar brand $(\mathrm{t}(295)=71.34, \mathrm{p}<0.001)$.

The effect size of the familiarity was big $\left(\eta_{\mathrm{p}}{ }^{2=} 0.80\right)$, while that of the motivational orientations was small $\left(\eta_{\mathrm{p}}{ }^{2=} 0.06\right)$. Familiarity would have a greater effect than motivational orientations on skepticism. Thus, H1c was evinced.

Table 2

ANOVA Analysis of Main and Interaction Effects for Skepticism

\begin{tabular}{|c|c|c|c|c|c|c|}
\hline & & & \multicolumn{2}{|c|}{ F } & $\mathrm{p}$ & $\eta_{\mathrm{p}}^{2}$ \\
\hline \multicolumn{7}{|l|}{ Main effects } \\
\hline \multicolumn{4}{|l|}{ Motivational Orientation (MO) } & 15.62 & 0.000 & 0.06 \\
\hline \multicolumn{3}{|l|}{ Familiarity $(\mathrm{F})$} & \multicolumn{2}{|c|}{1197.59} & 0.000 & 0.80 \\
\hline \multicolumn{7}{|l|}{ Interaction effect } \\
\hline \multicolumn{3}{|l|}{$\mathrm{F} \times \mathrm{MO}$} & \multicolumn{2}{|c|}{0.99} & 0.32 & 0.00 \\
\hline \multicolumn{7}{|c|}{ Group differences of skepticism between familiar and unfamiliar brands by controlling Motivational Orientations } \\
\hline & \multicolumn{2}{|c|}{ a familiar brand } & \multicolumn{2}{|c|}{ an unfamiliar brand } & & \\
\hline & M & $(\mathrm{SD})$ & M & (SD) & $\mathrm{t}$ & $\begin{array}{l}\text { Cohen's } \\
\text { d }\end{array}$ \\
\hline Promotion & 2.08 & 0.57 & 3.44 & 0.46 & $\mathrm{t}_{171}=26.21 * * *$ & 2.63 \\
\hline Prevention & 2.31 & 0.42 & 3.59 & 0.51 & $\mathrm{t}_{123}=22.65^{* * *}$ & 2.74 \\
\hline \multicolumn{7}{|l|}{$* * \mathrm{p}<.01 . * * * \mathrm{p}<.001$} \\
\hline \multicolumn{7}{|c|}{ Group differences for skepticism between the motivational orientation groups by controlling familiarity } \\
\hline & \multicolumn{2}{|c|}{ Promotion } & \multicolumn{2}{|c|}{ Prevention } & & \\
\hline
\end{tabular}




\begin{tabular}{l|c|c|c|c|lc}
\hline & $\mathrm{M}$ & (SD) & $\mathrm{M}$ & (SD) & $\mathrm{t}$ & $\begin{array}{c}\text { Cohen's } \\
\mathrm{d}\end{array}$ \\
\hline Familiar & 2.08 & 0.57 & 2.31 & 0.42 & $\mathrm{t} 295=71.34 * * *$ & 0.46 \\
\hline Unfamiliar & 3.44 & 0.46 & 3.59 & 0.51 & $\mathrm{t} 295=123.84 * * *$ & 0.31 \\
\hline$* * \mathrm{p}<0.01 . * * \mathrm{p}<0.001$.
\end{tabular}

For positive emotions, Participants' positive emotion regarding the two online video advertisements was analyzed using repeated measures ANOVA. The results confirmed that there were significant main effects of brand familiarity $(F(1,294)=323.89, p<0.0001)$, and motivational orientations $(F(1,294)=140.40, p<0.0001)$ on positive emotion.

Simple t-tests confirmed hypothesis H2a that the familiar brand $(\mathrm{t}(295)=78.86, \mathrm{p}<0.0001)$ evokes more positive emotions than unfamiliar brand $(\mathrm{t}(295)=64.75, \mathrm{p}<0.0001)$.

The hypothesis H2b regarding two groups' positive emotion was also supported: Paired t-tests confirmed the influence of brand familiarity, with the promotion-oriented group responding more positively than the prevention group ( $\mathrm{M}$ promotion $=3.80, \mathrm{M}$ prevention $=2.89, \mathrm{t}(295)=78.86, \mathrm{p}<0.001)$ to the unfamiliar brand $(\mathrm{M}$ promotion $=2.93, \mathrm{M}$ prevention $=2.34, \mathrm{t}(295)=65.75, \mathrm{p}<0.0001)$.

The interaction effect of motivational orientation and brand familiarity on positive emotions was found to have a significant interaction effect $(\mathrm{F}(1,294)=13.58, \mathrm{p}=0.0001)$ as shown in Table 3 . Thus, H2c cannot be evinced because it can be either main effects of brand familiarity and motivational orientations or interaction effects of the both.

Table 3

ANOVA Analysis of Main and Interaction Effects on Positive emotions

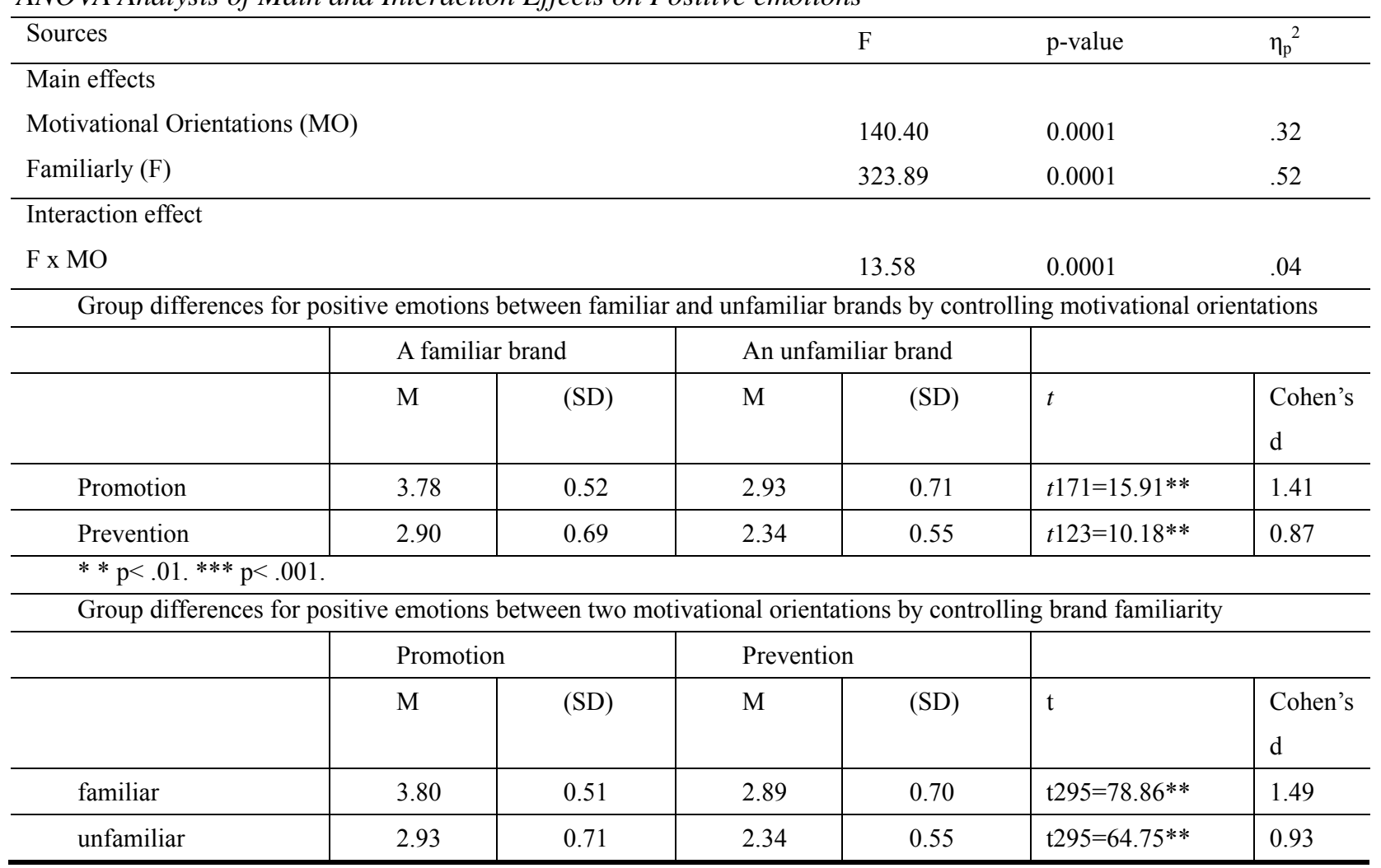


$* * \mathrm{p}<0.01 . * * * \mathrm{p}<0.001$

\section{Discussion}

Regarding English online video advertisements, for those individuals in non-English speaking regions, the results of study 1 confirm the significant effects of brand familiarity and motivational orientation on skepticism and positive emotion. The item features that address participants' chronic motivational orientations were considered. The outcomes of skepticism and positive emotions regarding English advertisements support most our hypotheses. We were also alerted the significant interactions between motivation orientation and brand familiarity with regard to positive emotion but not skepticism. Thus, study 2 was conducted to identify the participants' motivational orientation related to English so as to reconfirm the hypotheses.

\section{Study 2}

The participants in study 2 were measured for their motivational orientation related to English (MOE). The stimuli and procedure for all major aspects of study 2 were identical to those of study 1 .The participants were 345 undergraduates who were all enrolled in English as a foreign language classes. They had scored an average of 350 on TOEIC. Extra credit was provided for participating in the study. This sampling is relevant to the study since the participants' competence and the effect of the English advertising message on them rely on their knowledge of English (Luna \& Peracchio, 2001).

\section{Method}

The questionnaire presented a pool of eighteen items specifically referring to PROE and PVOE which was tailored and modified from Summerville and Roese's (2008) study. After item analysis, 18 items were selected in the questionnaire as MOE. Two forms of the first part of the questionnaire were counterbalanced over 10 classes to remove concerns about order effects on the promotion and prevention constructs. Nine items of promotion made reference to positive outcomes, ambition, achievement, and success in English learning. A sample item is "I typically focus on the success I hope to achieve in English learning." Conversely, the nine items on the factor of prevention made reference to failure, loss, obligation, and anxiety in English learning. For example, "Right now, I am concerned about missing out on positive outcomes in English learning" (see Appendix A). All items were presented on a one "strongly disagree" to five "strongly agree" Likert scale. A participant's motivational orientation is calculated in the same manner as in study 1. Among the 345 participants, $143(41.4 \%)$ were grouped as having a prevention orientation in English, and 202 (58.6\%) as having a promotion orientation.

Similar to study 1, a paired t-test indicated that there was a significant difference in the scores for brand familiarity $(\mathrm{t}(345)=2.11, \mathrm{p}<0.001)$ between New Balance $(\mathrm{M}=4.19, \mathrm{SD}=0.92)$ and Skechers $(\mathrm{M}=2.07$, $\mathrm{SD}=.98$ ). Exploratory factor analysis revealed clean loading patterns for MOE (18 items), Familiarity (three items) Positive Emotions (eight items) and Skepticism (three items). The Cronbach's $\alpha$ values for all the measures ranged from 0.74 to 0.93 (see Table 4). The factor loadings in the Structure Matrix (see Appendix B) are all above 0.32 (Preacher \& MacCallum, 2003; Fabrigar, Wegener, MacCallum, \& Strahan, 1999).

Table 4

Familiar Brand vs.Unfamiliar Brand

Study 2 The number of items in each construct and Cronbach's $\alpha$ 


\begin{tabular}{lll}
\hline & Item number & Cronbach's $\alpha$ \\
\cline { 2 - 3 } English Promotion & 9 & 0.80 \\
English Prevention & 9 & 0.83 \\
Familiarity & 3 & 0.87 \\
Skepticism & 3 & 0.74 \\
Positive Emotions & 8 & 0.93 \\
\hline
\end{tabular}

\section{Results}

Exploratory factor analysis revealed clean loading patterns (above 0.3) for MOE (18 items), Familiarity (three items), Skepticism (three items) and Positive Emotions (eight items). The Cronbach's $\alpha$ values for all the measures ranged from 0.74 to 0.93 . There was a significant difference in the scores for brand familiarity ( $\mathrm{t}(345)$ $=2.11, \mathrm{p}<0.001)$ between New Balance $(\mathrm{M}$ familiar $=4.19, \mathrm{SD}=0.92)$ and Skechers $(\mathrm{M}$ unfamiliar=2.07, $\mathrm{SD}=0.98)$.

ANOVA (see Table 5) showed that there was a significant main effect of motivational orientation on participants' skepticism $(\mathrm{F}(1,343)=68.28, \mathrm{p}<0.01)$ and brand familiarity $(\mathrm{F}(1,343)=221.12, \mathrm{p}<0.01)$.

Simple t-tests confirmed H1a the influence of the unfamiliar brand $(\mathrm{t}(343)=10.52, \mathrm{p}<0.0001)$ and the unfamiliar brand $(\mathrm{t}(343)=2.05, \mathrm{p}<0.001)$ on skepticism.

There is a significant effect of the unfamiliar brand advertisement $(\mathrm{M}$ prevention/unfamiliar $=4.03, \mathrm{M}$ promotion/unfamiliar $=3.17, \mathrm{p}<0.0001)$ the familiar brand advertisement with a higher level of skepticism on the part of the prevention-oriented group (M prevention/familiar=2.81, $\mathrm{M}$ promotion/familiar=2.64, $\mathrm{p}<0.0001$ ), so H1b was supported.

The interaction effect of motivational orientation and brand familiarity on skepticism was found to be considerably significant $(\mathrm{F}(1,343)=38.02, \mathrm{p}<0.01)$. H1c was not supported.

Table 5

ANOVA Analysis of Main and Interaction Effects for Skepticism

\begin{tabular}{lccc}
\hline & $\mathrm{F}$ & $\mathrm{p}$ & $\eta_{\mathrm{p}}{ }^{2}$ \\
\hline Main effect & & & \\
Motivational Orientation in English (MOE) & 68.276 & 0.001 & 0.17 \\
Familiarity (F) & 221.12 & 0.001 & 0.40 \\
\hline Interaction effect & & & \\
F x MOE & 38.02 & 0.001 & 0.10 \\
\hline
\end{tabular}

Group differences of skepticism between familiar and unfamiliar brands by controlling motivational orientation related to English

\begin{tabular}{c|l|l|l|l|l|l}
\hline & \multicolumn{2}{|c|}{ a familiar brand } & \multicolumn{2}{|c|}{ an unfamiliar brand } & \multicolumn{2}{l}{} \\
\hline & $\mathrm{M}$ & $(\mathrm{SD})$ & $\mathrm{M}$ & $(\mathrm{SD})$ & $\mathrm{t}$ & Cohen's \\
\hline Promotion & 2.64 & 0.78 & 3.17 & 0.85 & $\mathrm{t} 201=7.10^{* *}$ & 0.65 \\
\hline Prevention & 2.81 & 0.70 & 4.03 & 0.58 & $\mathrm{t} 142=15.29 * *$ & 1.90 \\
\hline
\end{tabular}

$* * \mathrm{p}<.001, * \mathrm{p}<.05$

Group differences for skepticism between the motivational orientations related to English groups by controlling brand familiarity.

\begin{tabular}{l|l|l|l|l|l|l}
\hline & \multicolumn{2}{|c|}{ Promotion } & \multicolumn{2}{|c}{ Prevention } & \multicolumn{2}{l}{} \\
\hline & $\mathrm{M}$ & $(\mathrm{SD})$ & $\mathrm{M}$ & (SD) & $\mathrm{t}$ & Cohen's \\
\hline Familiar & 2.64 & 0.78 & 2.81 & 0.70 & $\mathrm{t} 343=2.05^{*}$ & 0.23 \\
\hline
\end{tabular}




\begin{tabular}{l|l|l|l|l|l|l}
\hline Unfamiliar & 3.17 & 0.85 & 4.03 & 0.58 & $\mathrm{t} 343=10.54 * *$ & 1.18 \\
\hline$* \mathrm{p}<0.05 . \quad * * * \mathrm{p}<0.001$.
\end{tabular}

ANOVA (see Table 6) was used to test $\mathrm{H} 2 \mathrm{a}$ and showed a significant main effect of motivational orientation $(\mathrm{F}(1,343)=256.82, \mathrm{p}<0.001)$ and brand familiarity $(\mathrm{F}(1,343)=189.31, \mathrm{p}<0.01)$. There was also a significant effect of motivation $(\mathrm{F}(1,343)=256.82, \mathrm{p}<0.001)$ for the familiar brand advertisement with more positive emotions ( $\mathrm{M}$ promotion/familiar=4.10, $\mathrm{M}$ prevention/familiar=3.40, $\mathrm{p}<0.001$ ), and for the unfamiliar brand advertisement $(\mathrm{M}$ promotion/unfamiliar=3.04, M prevention/unfamiliar $=2.71, \mathrm{p}<0.001)$.

An independent $t$-test was conducted to test the hypothesis H2b that the PROE group ( $\mathrm{t}(201)=12.86$, $\mathrm{p}<0.001)$ evoke more positive emotions than the PVOE group ( $(142)=5.88, \mathrm{p}<0.001)$.

The interaction effect of motivational orientation and brand familiarity on positive emotions was found to be significant $(\mathrm{F}(1,343)=17.99, \mathrm{p}<0.001)$. $\mathrm{H} 2 \mathrm{c}$ was not supported.

Table 6

ANOVA Analysis of Main and Interaction Effects for Positive Emotions

\begin{tabular}{lccc}
\hline & $\mathrm{F}$ & $\mathrm{p}$ & $\eta_{\mathrm{p}}{ }^{2}$ \\
\hline Main effect & & & \\
Motivational Orientation in English (MOE) & 256.82 & 0.001 & .43 \\
Familiarity (F) & 189.31 & 0.001 & .36 \\
\hline Interaction effect & & & .05 \\
F x MOE & 17.99 & 0.001 & .05 \\
\hline
\end{tabular}

Group differences for positive emotions between familiar and unfamiliar brands by controlling motivational orientation related to English

\begin{tabular}{l|c|l|l|l|l|l}
\hline & \multicolumn{2}{|c|}{$\begin{array}{l}\text { A } \\
\text { familiar } \\
\text { brand }\end{array}$} & \multicolumn{2}{c|}{$\begin{array}{c}\text { An } \\
\text { unfamiliar brand }\end{array}$} & \\
\hline & $\mathrm{M}$ & $(\mathrm{SD})$ & $\mathrm{M}$ & $\mathrm{SD})$ & $\mathrm{t}$ & Cohen's d \\
\hline Promotion & 4.10 & 0.58 & 3.40 & 0.66 & $\mathrm{t} 201=12.86^{* *}$ & 1.13 \\
\hline Prevention & 3.04 & 0.64 & 2.70 & 0.63 & $\mathrm{t} 142=5.88^{* *}$ & 0.54 \\
\hline
\end{tabular}

Group differences for positive emotions between two motivational orientations related to English by controlling brand familiarity.

\begin{tabular}{l|r|l|r|r|l|l}
\hline & \multicolumn{2}{|l|}{ Promotion } & \multicolumn{2}{c|}{ Prevention } & \\
\hline & $\mathrm{M}$ & $(\mathrm{SD})$ & $\mathrm{M}$ & $(\mathrm{SD})$ & $\mathrm{t}$ & Cohen's \\
\hline familiar & 4.10 & 0.58 & 3.04 & 0.64 & $\mathrm{t} 343=15.87^{*}$ & 1.74 \\
\hline unfamiliar & 3.40 & 0.66 & 2.70 & 0.63 & $\mathrm{t} 343=10.00^{* *}$ & 1.08 \\
\hline
\end{tabular}

\section{Discussion}

The results of Study 2 are almost equivalent to those reported for Study 1. In Study 2, regarding online video advertisements in English, for individuals in non-English speaking regions, promotion and prevention orientation were related to English. In terms of MOE, PROE participants also had higher positive emotions regarding the unfamiliar brand ad than the PVOE participants did toward the familiar brand advertisement. Crucially, the effect size of MOE on skepticism increased compared to motivational orientation in study 1 . In terms of brand familiarity, the PVOE individuals displayed a significantly higher degree of skepticism than the 
PROE individuals. The asymmetry in the results was approximately consistent across the two studies employing different participants, using chronic motivational orientation vs. motivational orientation related to English.

\section{Conclusion}

This study makes a major contribution to the field of motivational orientations and brand familiarity in online video advertisements in English for individuals in non-English speaking regions. This study explicitly shows that, in non-English speaking regions, the outcomes of consumers' skepticism and positive emotions regarding online video advertising can be interfered with by the interaction between motivational orientations and brand familiarity. Four important findings are discovered:

First, for skepticism, the effect of brand familiarity is greater than that of motivational orientations.

Second, for positive emotions, the effect is influenced by both the interaction effect of brand familiarity and motivational orientation and MOE.

Third, for online English video advertisements of both familiar and unfamiliar brands, promotion-orientated individuals display a higher degree of positive emotions than prevention-orientated individuals.

Fourth, PROE individuals display a higher degree of positive emotions than PVOE individuals, regardless of familiar or unfamiliar brand.

The findings apply to those consumers using English as an L2, implying that motivational orientations can be an effective linguistic segmentation tool in building a new brand image if advertisements are targeted at international consumer segmentation.

The findings of this study contribute to our understanding of online English video advertising. When it comes to online English video advertising in non-English speaking regions, recognizing consumers' motivational orientation can facilitate both sides of the cultural ideals which often form the foundation for attraction in international market communications. For unfamiliar brands, ad information can provoke both skepticism and positive emotions. Recognizing the motivation orientation towards which consumers tend to be leaning can facilitate both sides of the cultural ideals which often form the foundation for attraction in international market communications.

When using motivational orientations as a tool of market segments, promotion-orientation is the priority of the target group. For those promotion-oriented individuals, rational appeal can reduce their skepticism, or emotional appeal can gain their positive emotions. For prevention-focused individuals, the brand's familiarity can be highlighted and the use of brand strength can be emphasized.

With the effect of regulatory fit, consumers will feel right and strengthen their engagement (Higgins, 1997; Jain, Lindsey, Agrawal, \& Maheswaran, 2007). Extant findings in the literature also show when people experience regulatory fit, their attitude toward a product becomes more positive, confidence in their judgment strengthens, their assessment of the product's value increases, and their ad persuasion increases (Aaker \& Lee, 2001; Kim \& Sung, 2013). As marketers consider adopting motivational orientation related to English as a segment tool, they can exploit the adventurous spirit of individuals with PROE to attract their attention. Nevertheless, integration of captions or dubbing and voice-over in the local language can be considered in the advertisements, or whether it is necessary to recreate the advertisement in the target local market when targeting consumers with a PVOE who have higher skepticism and lower positive emotions. The role of foreign 
and local languages in online marketing should not be overlooked.

For unfamiliar brands, MOE is a tremendous strategy for marketing segment since the findings indicate that motivation orientation has a superior result. For example, the advertisement of the Ironman Triathlon is unfamiliar to people in Taiwan. It uses excitement and compassion as its emotional appeal. Despite the fact of its unfamiliarity, all qualified athletes actively enrolled in the event with a full quota for all the Ironman 70.3 races. One of the successful factors is their online English video, as a result of which they are gaining more popularity in Taiwan (Ironman Taiwan).

In this study, there is merely one selected product which serves as one functional category, namely, toning shoes in online video advertisements. For future studies, it is suggested that more varieties of products be adopted, such as high tech products or hedonic products, to examine regulatory individuals' responses to the advertisements. Secondly, only university students in Taiwan were sampled. The level of participants' involvement should be taken into account since it is an important variable when examining ad effectiveness (Te'eni-Harari, Lehman-Wilzig, \& Lampert, 2009).

Language has a significant impact on people and their behavior. This is particularly true in the fields of marketing and advertising since the language can be utilized as the thoughts and emotions of the individuals. Future research comparing English with local languages across non-English speaking regions will further increase understanding of the effectiveness of the English language in online video advertising. Various types of online advertising can be considered to ensure the most effective video advertising tactics and methods and to achieve greater commonality and efficiencies. It should not be overlooked when global marketers target non-English-speaking regions. The differences between consumers' motivational orientation may have an impact on promoting brands and products to different non-English-speaking regions in online video advertising.

\section{References}

Aaker, J. L., \& Lee, A. Y. (2006). Understanding regulatory fit. Journal of Marketing Research, 43(1), 15-19.

Aaker, J., \& Lee, A.Y. (2001). I seek pleasure and we avoid pains: The role of self-regulatory goals in information processing and persuasion. Journal of Consumer Research, 28 (4), 33-49.

Ahn, S., \& Ferle, C. L. (2008), Recall \& recognition for brand names and body copy: A mixed-language approach. Journal of Advertising, 37 (3), 107-117.

Alba, J., \& Hutchinson, J. W. (2000). Knowledge calibration: What consumers know and what they think they know. Journal of Consumer Research, 27(2), 123-156.

Assael, H. (1988). Consumer behavior and marketing action (Vol. 3). Boston: Kent Publishing Company.

Assael, H. (1998). Consumer behavior and marketing action (6th ed.). Cincinnati, Ohio: South-Western College Publishing.

Baek, T. H., \& Reid, L. N. (2013). The interplay of mood and regulatory focus in influencing altruistic behavior. Psychology \& Marketing, 30(8), 635-646.

Bickart, B. A., \& Ruth, J. A. (2012). Green eco-seals and advertising persuasion. Journal of Advertising, 41(4), 51-67.

Bolte, A., Goschke, T., \& Kuhl, J. (2003). Emotion and intuition effects of positive and negative mood on implicit judgments of semantic coherence. Psychological Science, 14(5), 416-421.

Callister, M. A., \& Stern, L. A. (2007). The role of visual hyperbole in advertising effectiveness. Journal of Current Issues \& Research in Advertising, 29(2), 1-14.

Campbell, M. C., \& Keller, K. L. (2003). Brand familiarity and advertising repetition effects. Journal of Consumer Research, 30(2), 292-304.

Cesario, J., \& Higgins, E. (2008). Making message recipients feel right: How nonverbal cues can increase persuasion. Psychological Science, 19(5), 415-420.

Chang, C. (2010). Message framing and interpersonal orientation at cultural and individual levels. International Journal of 
Advertising, 29(5), 765-794.

Chapman, A. (2013). Tailoring websites to the user for increased conversion: Case study of Wild Dunes Resort. Journal of Digital \& Social Media Marketing, 1(2), 136-143.

Chernev, A. (2004). Goal-attribute compatibility in consumer choice. Journal of Consumer Psychology, 14(1), 141-150.

Cohen, J. (1988). Statistical power analysis for the behavioral sciences (2nd ed.). Hillsdale, NJ: Erlbaum.

Cunningham, R. C. L., \& Johnson, M. K. (2005). Neural correlates of evaluation associated with promotion and prevention regulatory focus. Cognitive, Affective, \& Behavioral Neuroscience, 5(2), 202-211.

Dens, N., \& De Pelsmacker, P. (2010). How advertising strategy effects brand and USP recall for new brands and extensions. International journal of advertising, 29(2), 165-194.

Dörnyei, Z. (2003). Attitudes, orientations, and motivations in language learning: Advances in theory, research, and applications. Language Learning, 53(S1), 3-32.

Evans, D. S. (2009). The online advertising industry: Economics, evolution, and privacy. Journal of Economic Perspectives, Forthcoming, 23(3), 37-60.

Fabrigar, L. R., Wegener, D. T., MacCallum, R. C., \& Strahan, E. J. (1999). Evaluating the use of exploratory factor analysis in psychological research. Psychological Methods, 4(3), 272-299.

Forbes-Riley, K., \& Litman, D. J. (2009). Adapting to Student Uncertainty Improves Tutoring Dialogues. Proceedings from AIED: The 14th International Conference on Artificial Intelligence in Education (pp. 33-40), Brighton, UK.

Förster, J., \& Higgins, E. T. (2005). How global versus local perception fits regulatory focus. Psychological Science, 16(8), 631-636.

Gardner, R. C., \& Lambert, W. E. (1972). Attitudes and motivation: second language learning. Rowley, MA: Newbury House.

Gross, J. (2001). Emotional regulation in adulthood: Timing is everything. Current Directions in Psychological Science, 10(6), 214-219.

Ha, H.Y., \& Perks, H. (2005). Effects of consumer perceptions of brand experience on the web: Brand familiarity, satisfaction and brand trust. Journal of Consumer Behaviour, 4(6), 438-452.

Haws, K. L., Dholakia, U. M., \& Bearden, W. O. (2010). An assessment of chronic regulatory focus measures. Journal of Marketing Research, 47(5), 967-982.

Heath, R. (2009). Emotional engagement: How television builds big brands at low attention. Journal of Advertising Research, $49(1), 62-73$.

Heath, T. B., DelVecchio, D. \& McCarthy, M. S (2011). The asymmetric effects of extending brands to lower and higher quality. Journal of Marketing, 75(4), 3-20.

Higgins, E. T. (1997). Beyond pleasure and pain. American Psychologist, 52(12), 1280-1300.

Higgins, E. T., \& Tykocinski, O. (1992). Self-discrepancies and biographical memory: Personality and cognition at the level of psychological situation. Personality and Social Psychology Bulletin, 18(10), 527-535.

Higgins, E. T., Shah, J., \& Friedman, R. (1997). Emotional responses to goal attainment: Strength of regulatory focus as moderator. Journal of Personality and Social Psychology, 72(3), 515-525.

Holbrook, M.B., \& Batra, R. (1987). Assessing the role of emotions as mediators of consumer responses to advertising. Journal of Consumer Research, 14(12), 404-420.

Holden, S. J. S., \& Vanhuele, M. (1999). Know the name, forget the exposure: Brand familiarity versus memory of exposure context. Psychology and Marketing, 16(6), 479-496.

Homer, P. M (2006).Relationships among ad-induced affect, beliefs, and attitudes. Journal of Advertising, 35(1), 35-51.

Jain, S. P., Lindsey, C., Agrawal, N., \& Maheswaran, D. (2007). For better or for worse? Valenced comparative frames and regulatory focus. Journal of Consumer Research, 34(1), 57-65.

Kim, D. H., \& Sung, Y. (2013). Gucci versus Old Navy: Interplay of brand personality and regulatory focus in advertising persuasion. Psychology \& Marketing, 30(12), 1076-1087.

Kirmani, A., \& Zhu, R. (2007). Vigilant against manipulation: The effect of regulatory focus on the use of persuasion knowledge. Journal of Marketing Research, 44(4), 688-701.

Koslow, S. (2000). Can the Truth Hurt? How honest and persuasive advertising can unintentionally lead to increased consumer skepticism. Journal of Consumer Affairs, 34(4), 245-267.

Leavitt, C. (1970). A multidimensional set of rating scales for television commercials. Journal of Applied Psychology, 54(5), 427-429.

Lee, T. R., Lin, J. H., Liao, L. W. C., \& Yeh, T. H. (2013). Managing the positive and negative characteristics of enterprise 
microblog to attract user to take action through the perspective of behavioural response. International Journal of Management and Enterprise Development, 12(4), 363-384.

Liang, B., Cherian, J., \& Liu, Y. (2010). Concrete thinking or ideographic language: Which is the reason for Chinese people's higher imagery-generation abilities? International journal of consumer studies, 34(1), 52-60.

Luna, D., \& Peracchio, L. A. (2001). Moderators of language effects in advertising to bilinguals: A psycholinguistic approach. Journal of Consumer Research, 28(2), 284-295.

Luna, D., \& Peracchio, L.A. (2005). Advertising to bilingual consumers: The impact of code-switching on persuasion. Journal of Consumer Research, 31(4), 760-765.

Obermiller, C., \& Spangenberg, E. R. (1998). Development of a scale to measure consumer skepticism towards advertising. Journal of Consumer Psychology, 7(2), 159-186.

Percy, L., \& Rossiter, J. R. (1992). A model of brand awareness and brand attitude advertising strategies. Psychology and Marketing, 9(4).

Peytcheva, M. (2013). Professional skepticism and auditor cognitive performance in a hypothesis-testing task. Managerial Auditing Journal, 29(1), 27-49.

Pham, M., \& Higgins, E. T. (2005). Promotion and prevention in consumer decision-making. In S. Ratneshwar, \& D. G. Mick(Eds.), Inside Consumption: Frontiers of research on consumer motives, goals, and desires (pp. 9-43). London: Routledge.

Porcari, J., Greany, J., Tepper, S., Edmonson, B., Foster, C., Sandve, M. \& Anders, M. (2010). Will toning shoes really give you a better body? Retrieved from http://www.acefitness.org/certifiednewsarticle/720/

Preacher, K. J., \& MacCallum, R. C. (2003). Repairing Tom Swift's electric factor analysis machine. Understanding Statistics, 2(1), 13-43.

Rampl, L. V., \& Kenning, P. (2013). Employer brand trust and affect: Linking brand personality to employer brand attractiveness. European Journal of Marketing, 48(1/2), 11.

Sohn, S. H. (2013). Living in a consumer society: Adaptation experiences of North Korean youth defectors in South Korea. Asian and Pacific Migration Journal, 22(1), 109.

Soopramanien, D. (2011). Conflicting attitudes and scepticism towards online shopping: The role of experience. International Journal of Consumer Studies, 35(3), 338-347.

Summerville, A., \& Roese, N. J. (2008). Self-report measures of individual differences in regulatory focus: A cautionary note. Journal of Research in Personality, 42(1), 247-254.

Sung, Y., \& Kim, J. (2010). Effects of brand personality on brand trust and brand affect. Psychology \& Marketing, 27(7), 639-661.

Sung, Y.,\& Choi, S. M. (2011). Increasing power and preventing pain. Journal of Advertising,40 (1), 71-86.

Te'eni-Harari, T., Lehman-Wilzig, S. N., \& Lampert, S. I. (2009). The importance of product involvement for predicting advertising effectiveness among young people. International Journal of Advertising, 28, (2), 203-229.

Teixeira, T., Wedel, M., \& Pieters, R. (2012). Emotion-Induced engagement in Internet video advertisements. Journal of Marketing Research, 49(2), $144-159$.

Truong, Y., McColl, R., \& Kitchen, P. (2010). Practitioners" perceptions of advertising strategies for digital media. International Journal of Advertising, 29(5), 709-725.

Tse, D. K., Belk, R. W., \& Zhou, N. (1989). Becoming a consumer society: A longitudinal and cross-cultural content analysis of print ads from Hong Kong, the People's Republic of China, and Taiwan. Journal of Consumer Research, 15(4), 457-472.

Verwijmeren, T., Karremans, J. C., Bernritter, S. F., Stroebe, W., \& Wigboldus, D. H. (2013). Warning: You are being primed! The effect of a warning on the impact of subliminal ads. Journal of Experimental Social Psychology, 49(6), 1124-1129.

Wallace, M. J. (1991). Training foreign language teachers: A reflective approach. Cambridge University Press, 21-23.

Wang, J., \& Lee, A. Y. (2006). The role of regulatory focus in preference construction. Journal of Marketing Research, 43(1), 28-38.

Watson, D., Clark, L. A., \& Tellegen, A. (1988). Development and validation of brief measures of positive and negative affect: The Panas scales. Journal of personality and social psychology, 54(6), 1063.

Wolin, L. D. (2003). Gender issues in advertising an oversight synthesis of research. Journal of Advertising Research, 43 (1), 111-129.

Wyer, R. S. Jr. (2002). Language and advertising effectiveness: Mediating influences of comprehension and cognitive elaboration. 
Psychology and Marketing, 19(July-August), 693-712.

Yen, C., Chao, S., \& Lin, C. (2011). Field testing of regulatory focus theory. Journal of Applied Social Psychology, 41 (6), $1565-1581$.

Yoh, T. (2005).Parent, peer, and TV influences on American teen athletic shoe purchasing. International Journal of Sport Management, 1 (2), 180-189.

Zhang, S., \& Schmitt, B. H. (2004). Activating sound and meaning: The role of language proficiency in bilingual consumer environments. Journal of Consumer Research, 31(1), 220-228.

Zhao, G., \& Pechmann, C. (2007). The impact of regulatory focus on adolescents' response to antismoking advertising campaigns. Journal of Marketing Research, 44(4), 671-68.

\section{Appendix A}

Study 1 Structure Matrix

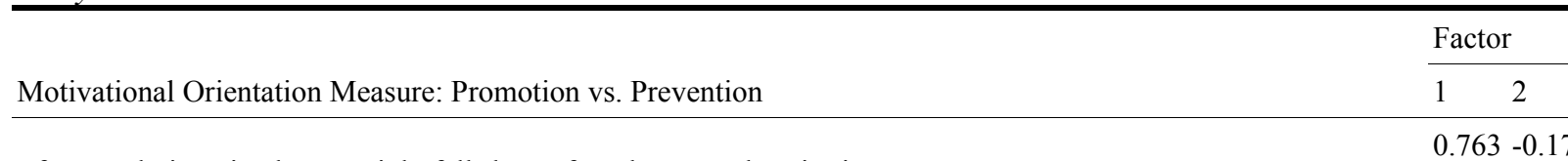

I frequently imagine how I might fall short of my hopes and aspirations.

I often imagine myself experiencing bad things that I fear might happen to me.

$0.727-.011$

I frequently worry that my future will be less successful than I hope.

$0.719-.069$

I frequently think about how I can prevent failures in my life.

0.6880 .279

When good things fail to materialize, it affects me strongly.

0.6830 .271

Right now, I am focused on protecting myself against negative outcomes.

0.6000 .403

I see myself as someone who has trouble reaching my "ideal-self"

(Fulfilling my hopes, wishes, and aspirations).

I am anxious that I will fall short of my responsibilities and obligations.

Right now, I am concerned about missing out on positive outcomes.

0.4620 .374

I see myself as someone who is primarily striving to reach my "ideal-self”,

0.0000 .691

- to fulfill my hopes, wishes, and aspirations.

I typically focus on the success I hope to achieve in the future.

0.2340 .654

I frequently imagine how I will achieve my hopes and aspirations.

I am confident that I can meet my responsibilities and obligations.

I am generally good at avoiding careless mistakes.

Right now, I am focused on avoiding negative outcomes.

When good things happen to me, it affects me strongly.

0.1400 .587

When good things happen to me, it affects me strongly.

0.2480 .562

$-0.130 .495$

Right now, I am focused on achieving positive outcomes.

0

I often imagine myself successfully preventing bad things from happening to me.

0.3610 .446

\begin{tabular}{|c|c|c|c|}
\hline \multirow{2}{*}{ English Ad is } & \multicolumn{3}{|c|}{ Factor } \\
\hline & 1 & 2 & 3 \\
\hline favorable & .918 & -.062 & .280 \\
\hline interesting & .913 & -.054 & .218 \\
\hline exciting & .891 & -.018 & .251 \\
\hline
\end{tabular}




\begin{tabular}{lccc} 
attentive & .883 & -.075 & .256 \\
inspiring & .874 & -.046 & .287 \\
enthusiastic & .864 & -.084 & .248 \\
active & .852 & -.071 & .260 \\
attractive & .831 & -.022 & .184 \\
skeptical & -.036 & .887 & -.049 \\
suspicious & -.112 & .884 & -.077 \\
distrustful & -.014 & .823 & -.067 \\
familiar & .284 & -.121 & .940 \\
well known & .267 & -.108 & .922 \\
seen before & .234 & .016 & .909 \\
\hline
\end{tabular}

\section{Appendix B}

Study 2 Structure Matrix

\begin{tabular}{|c|c|c|c|c|c|}
\hline \multirow{2}{*}{ Motivational orientation related to English: Promotion vs. prevention } & \multicolumn{5}{|c|}{ Factor } \\
\hline & 1 & 2 & 3 & 4 & 5 \\
\hline I typically focus on the success I hope to achieve in English language. & 0.34 & 0.23 & -0.17 & -0.09 & 0.81 \\
\hline Right now, I am focused on achieving positive outcomes in English learning. & 0.29 & 0.18 & -0.22 & -0.06 & 0.77 \\
\hline I am confident that I can meet my responsibilities and obligations in English learning. & 0.38 & 0.27 & -0.43 & -0.17 & 0.52 \\
\hline Right now, I am focused on protecting myself against negative outcomes in English learning. & 0.29 & 0.10 & -0.17 & -0.08 & 0.50 \\
\hline I frequently imagine how I will achieve my hopes and aspirations in English learning. & 0.20 & 0.11 & -0.15 & -0.07 & 0.49 \\
\hline I see myself as someone who is primarily striving to reach my 'ideal-self' in English learning. & 0.29 & 0.12 & -0.32 & -0.09 & 0.46 \\
\hline I am generally good at avoiding careless mistakes in English learning. & 0.21 & 0.16 & -0.13 & -0.11 & 0.44 \\
\hline When good things happen to me, it affects my English learning strongly. & 0.32 & 0.19 & -0.36 & -0.03 & 0.43 \\
\hline $\begin{array}{l}\text { I often imagine myself successfully preventing bad things from happening to me in English } \\
\text { learning. }\end{array}$ & 0.17 & 0.06 & 0.01 & -0.07 & 0.38 \\
\hline Right now, I am concerned about missing out on positive outcomes in English learning. & -0.26 & -0.02 & 0.79 & -0.01 & -0.11 \\
\hline I frequently worry that my English learning will be less successful than I hope. & -0.24 & 0.04 & 0.73 & 0.04 & -0.13 \\
\hline I frequently imagine how I might fall short of my hopes and aspirations in English learning. & -0.30 & -0.07 & 0.72 & 0.03 & -0.15 \\
\hline I am anxious that I will fall short of my responsibilities and obligations in English learning. & -0.30 & -0.17 & 0.63 & 0.12 & -0.22 \\
\hline I worry about making mistakes in English learning. & -0.30 & -0.10 & 0.54 & 0.09 & -0.15 \\
\hline When good things fail to materialize, it affects my English learning strongly. & -0.37 & -0.08 & 0.53 & -0.01 & -0.28 \\
\hline Right now, I am focused on avoiding negative outcomes in English learning. & -0.34 & -0.10 & 0.50 & 0.22 & -0.35 \\
\hline I see myself as someone who has trouble reaching my 'ideal-self' in English learning. & -0.31 & 0.05 & 0.48 & 0.16 & -0.27 \\
\hline $\begin{array}{l}\text { I often imagine myself experiencing bad things that I fear might happen to me in English } \\
\text { learning. }\end{array}$ & -0.25 & 0.04 & 0.42 & 0.12 & -0.11 \\
\hline Well-known & 0.08 & 0.92 & -0.02 & -0.11 & 0.14 \\
\hline Familiar & 0.08 & 0.80 & -0.03 & -0.05 & 0.16 \\
\hline Seen before & 0.12 & 0.78 & -0.06 & -0.04 & 0.21 \\
\hline Attentive & 0.85 & 0.10 & -0.36 & -0.15 & 0.36 \\
\hline Attractive & 0.83 & 0.08 & -0.34 & -0.20 & 0.35 \\
\hline Interested & 0.79 & 0.04 & -0.34 & -0.12 & 0.29 \\
\hline Favorable & 0.79 & 0.15 & -0.41 & -0.20 & 0.40 \\
\hline Enthusiastic & 0.78 & 0.16 & -0.35 & -0.20 & 0.39 \\
\hline Excited & 0.78 & 0.16 & -0.37 & -0.10 & 0.35 \\
\hline Inspired & 0.77 & 0.14 & -0.41 & -0.19 & 0.43 \\
\hline
\end{tabular}


